Meta

Journal des traducteurs

Translators' Journal

\title{
A General Theory of Translation (and of Language)
}

\section{Mariano Garcia-Landa}

Volume 35, numéro 3, septembre 1990

La traduction dans le monde hispanolusophone

URI : https://id.erudit.org/iderudit/003392ar

DOI : https://doi.org/10.7202/003392ar

Aller au sommaire du numéro

Éditeur(s)

Les Presses de l'Université de Montréal

ISSN

0026-0452 (imprimé)

1492-1421 (numérique)

Découvrir la revue

Citer cet article

Garcia-Landa, M. (1990). A General Theory of Translation (and of Language).

Meta, 35(3), 476-488. https://doi.org/10.7202/003392ar d'utilisation que vous pouvez consulter en ligne.

https://apropos.erudit.org/fr/usagers/politique-dutilisation/ 


\title{
A GENERAL THEORY OF TRANSLATION (AND OF LANGUAGE)
}

\author{
MARIANO GARCIA-LANDA \\ Brussels, Belgium
}

\begin{abstract}
This is a first and, therefore, schematic presentation of the elementary concepts of a translation theory based on the empirical difference between "message" (meaning meant) and sign chains as revealed by the practice of translation. The theory is presented in axiomatic manner. Three axioms define the theoretical world in which the propositions of the theory have meaning. Ten definitions present the difference between "message" and "sign chains" paving the way for the theorems which develop the main tenets of the theory. Inevitably, every theory of translation is also a general theory of language. The whole is written in a symbolic notation which allows for concept and proposition control ${ }^{1}$.
\end{abstract}

The great paradox in translation studies is that although much is being written by professional translators (see note 6) about many aspects of oral and written translation, no satisfactory general theory of translation exists capable of explaining the baffling but daily experience of professional translators whereby you can take an idea conveyed by words in a given language and express it in another language. This revealing experience proves not only that there is a difference between "message" (see definitions 1 and 2) and "sign chains" (def. 3) but also a difference between "message" and "sign system" (def. 6). This "message" is what speakers intend to say, that is, meaning meant. Therefore, our theory of translation is also a theory of meaning. We believe that only a theory of translation can explain what meaning meant is, and how it is produced. The reason is that translation is the only "language game" in which meaning meant is the object of the exercise inasmuch as all translating consists of concentrating on, and isolating and reproducing meaning meant, or, as we call it here too "the said as such". Translating reveals this: the meaning meant by speakers is a "perception" produced by the use of sign chains in rulegoverned social transactions (talking). What a theory of translation should explain is how it is possible that "perceptions" produced by people using sign systems in social situations can be reproduced by other (or the same) people using other sign systems.

The first thing we have to do is to postulate that there is a difference between

i) such perceptions produced with linguistic sign chains (def. 3 ), let us call them provisionally "linguistic perceptions" (LP) (defs. 1 and 2),

ii) and those very sign chains (including their semantic potential (def. 4)).

This difference allows us to say that although those Linguistic Perceptions ("ideas") can only be produced by sign chains used in social transactions, they are nevertheless different from such sign chains and their semantic potential. This means that there is no thinking outside language but that the "ideas" produced with sign chains in those social transactions we call "talking" are nevertheless different from those sign chains and their semantic potential and from the sign systems ("langue") from which those sign chains and those semantic potentials derive. We insist that this can only be seen and understood in the practice of that "talking game" we call translation. All translators worthy of that name know that there is such a difference in real life and the proof is that thousands of translations are done everyday on this planet and they succeed in re-producing the original "message" or "content", that is, they succeed in re-saying the "meaning

Meta, XXXV, 3, 1990 
meant" or the said as such (le déjà dit) (defs. 1 and 2) with other sign systems (def. 6). Therefore, we do not have to prove that such a difference exists, we have to take it for a fact of life and formulate a conceptual framework capable of taking into account that reality ${ }^{2}$.

But if we postulate a difference between i) Linguistic Perceptions ("ideas", "mental representations" or whatever we want to call them) produced in social talking transactions and ii) the sign chains, semantic potentials and sign systems used to that effect, what we are doing is constructing a theory of talking, that is, a general theory of language which is at the same time a theory of the mind, that is, a theory of thinking with sign systems as they are used by humans as a rule-governed social activity ${ }^{3}$. We would then say that thinking with sign systems (talking) is using sign systems in rule-governed social transactions to produce "extra-sensorial" perceptions ("ideas") 4 .

Our strategy in this schematic introduction is the following :

1) First, we formulate three axioms which set up the theoretical space in which our theorems are meaningful, that is to say, our theorems about the nature of language as talkingthinking and about translation have only meaning and are only useful and true in a world constructed with these three axioms.

2) Then we proceed to define in a very simple even naive manner (avoiding temporarily long philosophical discussions) the ten most elementary notions that we use in our propositions. We are aware that these definitions suggest serious philosophical problems but we ask our readers to take them in as they are for the time being and concentrate on what we can do with them. Once we perceive what we can do with them - namely, formulate a general theory of language - we could go back to the definitions and refine them, increase their number, etc. 5 . We promise not to introduce here any other notion or concept beyond those ten and we hope that they are sufficiently defined.

3) Then we proceed to formulate the specific propositions of the theory saying things about talking-thinking (commonly called "language") and about translation. These propositions are called here "theorems". Their number is not limited. We present only the first few.

The first one is the model of the social transaction of language (talking-thinking). This is what all language games have in common, so to speak, the "foundation" of all language games. We call it the "act of talking" (or "language event") to avoid "speech act" in the Searlian sense which refers to something else. This model of the talking act is the answer to the question "what is language?". The answer is "language is talking". And talking (in our meaning of "talking-thinking" which means that all talking involves the most complicated kind of thinking humans can produce, namely, manipulating signs in their relationships to experiences, practices and perceptions) includes both oral talking and talking in writing. In short, talking-thinking is a social transaction in which people living in a given social linguistic network use sign systems (def. 6) in rule-governed social transactions rooted in social situations (def. 10) to produce with their perceptual-cognitive systems a social object called "linguistic percept" (LP) (defs. 1 and 2). Our thesis is that this social entity is the real object of "language", not the sign chains (def. 3) used to produce it. This of course has consequences on the philosophy of language-mind and on models of language processing and language events.

Once we have a model of "talking-thinking" we go over to the second theorem which says that translating is to set in motion a talking-thinking act to re-produce a Linguistic Percept that somebody else has produced in a previous talking-thinking act seconds or centuries before. According to this approach someone says something either orally or in writing in a given social talking act and then someone else (or the same person but playing a different role) speaks again to say again in a second talking-thinking act 
that particular something that has been previously said, seconds or centuries before. That particular something which has been said, the said as such (le déjà dit) or "meaning meant" (defs. 1 and 2), which is the linguistic perception produced by the social activity of saying something and understanding what has been said, is the real object of "language" and at any rate the main object of this theory.

We postulate that there exists in the real world a social entity (as defined in defs. 1 and 2) which is the product of the social use of sign systems in social transactions. This is the main idea developed by our three axioms and our ten definitions: to postulate the existence of this entity called here provisionally "Linguistic Percept" and to distinguish it clearly i) from the sign chains and semantic potentials used to produce it and ii) from the sign systems (def. 6) to which those sign chains and semantic potentials belong. The other theorems try to say something meaningful - but only in this axiomatic world about some of the muddles of translation discussion such as equivalence, literality, etc. This restricted version stops at these generalities. The fully developed version goes on to formulate theorems about the specific model of the act of writing (sometimes called "text") and, based on this, the specific model of written translation.

\section{THE THREE AXIOMS}

\section{AXIOM 1: Whatever is said with sign systems can be repeated with other sign chains of the same system}

There are two propositions here:

i) whatever is said with sign systems (def. 6) can be said with other sign chains (defs. 3 and 4) of the same sign system and

ii) sign systems are used to produce perceptions (which is that which is said or the said as such (defs. 1 and 2)). This axiom establishes, therefore, that there is a difference between what is said and the sign chains (and their semantic potentials) with which it is said and, second, it establishes the possibility of translation, which is another way of linguistic communication. (Axiom of repeatability)

\section{AXIOM 2: Translating is talking}

This axiom establishes that there is no essential difference between the act of translating and the act of talking. This means that translating is a language game whose object is to isolate and re-produce "meanings meant" (the said as such or le déjà dit) by speakers. It is understood that all talking involves a highly complex form of thinking, namely, "thinking with signs", that is, thinking which consists of manipulating sign systems and sign chains and analyzing their relationships with experiences, social practices and sensorial perceptions, which is probably the most complex form of thinking humans can produce. (Therefore, Machine Translation, even within a context of Artificial Intelligence, is by definition an impossible task because no system invented by man can reach the limits of the intelligence which invents it). "Translation" is a language game in which people play at saying again the said as such (le déjà dit). It is the only language game in which the said as such is the object. In all other language games the said as such is simply taken for granted. In translation it is re-produced. This, in turn, defines talking-thinking as the activity of producing a social entity called "linguistic perception". (Ideas are social objects)

\section{AXIOM 3: You do not translate words, you translate only the said as such}

This axiom determines what kind of translation we are talking about here. We are not talking about translating isolated words or isolated sentences but only about translating what is said in acts of talking (oral and written speech). It's no use complaining that translation will never be able to reproduce words (words of a poem, for example). Translation, by this axiomatic definition, only re-produces the said as such. It is, therefore, 
also useless to complain about the impossibility of "total translation". "Total translation" is just a misunderstanding or an abuse of language. It is akin to "total communication". All doubts about the possibility / difficulty of translation are just doubts about the impossibility/difficulty of language communication.

These three axioms define a theoretical world within which are going to be meaningful the following definitions and subsequent theorems ${ }^{6}$.

\section{THE TEN DEFINITIONS ${ }^{7}$}

$\begin{array}{lll}\text { No. } & \text { Symbol } & \text { Entity Defined } \\ \text { DEF. 1: } & \text { LPI } & \text { Linguistic percept intended } \\ \text { DEF. 2: } & \text { LPC } & \text { Linguistic percept comprehended } \\ \text { DEF. 3: } & \text { Xm } & \text { Surface structure of the sign chain used in the talk act } \\ \text { DEF. 4: } & \mathrm{Sm} & \text { Semantic potential of the sign chain used in the talk act } \\ \text { DEF. 5: } & \mathrm{F} & \text { Linguistic unit used in the talk act } \\ \text { DEF. 6: } & \text { L } & \text { Sign system } \\ \text { DEF. 7: } & \mathrm{H} & \text { Semantic system } \\ \text { DEF. 8: } & \mathrm{K} & \text { Knowledge base } \\ \text { DEF. 9: } & \mathrm{P} & \text { Beliefs, norms, practices } \\ \text { DEF. 10: } & \mathrm{G} & \text { Social situation (social context of the talk act) }\end{array}$

\section{DEFINITION No. 1: LINGUISTIC PERCEPT INTENDED Symbol: LPI}

What the speaker/writer intends to say is experienced subjectively as a mental representation. It can also be conceived as a meaning carried by intentionality. It is a social object. This social object which is "what I want to say", is produced in a rulegoverned social activity called "language" (talking-thinking). It is not, strictly speaking, a linguistic object in the sense that it does not belong to the "sign system" ("la langue" in Saussurian French) but to the "talking act" ("la parole" in Saussurian French). It is a perception, a "mental" or "socio-psychological" object: as I am about to speak/write I must have some kind of perception of what I am going to say. It is perceived by talking subjects as the mental object to which tends their intentionality. This social/mental object, although different from the sign chain, could not exist without "language", that is, without society, it is produced by the manipulations of linguistic signs in social situations (thinking).

\section{DEFINITION No. 2: LINGUISTIC PERCEPT AS COMPREHENDED Symbol: LPC}

This is what hearers understand, i.e., the perception or mental representation that hearers produce as a result of the "language comprehension process" which is a cognitive process called "thinking". The LPI intended by the speaker (production subject) is comprehended by the hearer (comprehension subject). The LPC is the end result of the comprehension process and as such, it is the object of cognitive psychology. The LPC is or should be a reproduction of the LPI if we believe in the possibility of communication through sign systems. We postulate that it is possible to produce and communicate ("procommunicate") perceptions through the use of sign systems and, therefore, we postulate some sort of identity between LPC and LPI. We can provisionally write this identity like this: $\mathbf{L P C}=\mathbf{L P I}$.

Both LPIs and LPCs are experienced by speakers subjectively as mental happenings (mental representations = I have an idea of what I want to say) but they are in fact a social object, as social as "language" rather than strictly speaking "psychological". LPIs 
and LPCs do not exist separately but both together, namely, inasmuch as the LPC is a reproduction of the LPI. I understand what I want to say and, therefore, my LPI becomes an LPC even before I speak. We can formally say that LPCs either englobe LPIs or both can be considered as their identity which we write provisionally LPC = LPI. As such they constitue what we can call a "perceptual space". Perceptual spaces are social objects like words. Words are at the same time social institutions (Saussure) and psychological or mental experiences of individuals. The provisional identity LPC $=$ LPI, as it stands, is a telepathy model. In real life there must be something physical, namely, sign chains, between those two poles. (See proposition 3c below). The identity sign "=" does not mean identity or equality in any mathematical or logical sense but rather some sort of "communication identity" (what you understand must somehow be "identical" to what I mean) which we have to postulate if we want to explain that people sometimes do understand each other in talking. Understanding each other can only mean that when I listen to what you want to say and to what you are actually saying I end up having a percept or mental representation which must somehow be sufficiently similar to the mental representation you wanted to convey. We will postulate, of course, the same kind of identity in the case of translation. (See Annex I)

DEFINITION No. 3: SURFACE STRUCTURE OF THE SIGN CHAIN Symbol: Xm

This is simply Chomsky's notion of "surface structure", not of any invented example but of the sign chain actually used (constructed and uttered) in social acts of talking/writing (see Axiom 3). There can be of course plenty of different surface structures, $\mathrm{Xm}, \mathrm{Xn}, \mathrm{Xp}, \mathrm{Xo}$, etc. When people talk they do many things manipulating linguistic signs, for example they construct sign chains to produce or get hold of mental representations and to transmit them to other people. Probably these two operations, namely, to produce and to communicate mental perceptions attached to sign chains, are one and the same thing. To talk is to say something (to produce and communicate something). Definition 1 says that what is said (produced and communicated) is an LPI. And this saying things (producing + communicating them) involves constructing sign chains. But those sign chains are different in kind from the mental percepts that people want to say (intended or comprehended). Sign chains are linguistic objects whereas those mental percepts are not linguistic objects even if, as it happens, they cannot exist without linguistic sign systems.

\section{DEFINITION No. 4: SEMANTIC POTENTIAL OF Xm Symbol: Sm}

This is Chomsky's notion of "deep structure" but with a difference, namely, in this definition the deep structure belongs to the grammar of the Xm before its use in a social act of talking. Any sign chain (any Xm) isolated from its social act of talking, or introduced as an example, has an open or hidden polysemic semantic structure. When that $\mathrm{Xm}$ is actually used in a social act of talking-thinking what was up to that point a mere semantic potential Sm materializes in an actual meaning (slightly different or very different from the appearence of the semantic potential). That is, the speakers use the semantic potential of sign chains to produce perceptions which might or might not be exactly what the semantic potential seemed to be. This is, of course, a daily experience of professional translators. The semantic potential of an isolated sign or of an isolated sign chain is their "dictionary meaning" (which is rarely of any use to translators!). Every isolated sign or sign chain has a semantic potential Sm and this means that they normally have several potential meanings. Native speakers are not aware of this polysemy of every isolated sign. and sign chain. English speakers will tend to think that, for example, the English word "claim" has always the same meaning because it is the same "word". In fact, it can be 
translated into French sometimes by "crédits", some other times by "revendications", some other times by "accidents" (in the context of insurance), and, therefore, "claims" has all those possibilities of meaning. The semantic potential Sm of an isolated sign or sign chain is the set of its possible actual meanings: $\mathrm{Sm}=(\mathrm{S} 1, \mathrm{~S} 2, \mathrm{~S} 3 \ldots)$. (This is a definition of polysemy.)

\section{DEFINITION No. 5: SIGN CHAIN UNIT ACTUALLY USED Symbol: F}

Linguistic sign chains uttered in real life situations (in talking-thinking) do not necessarily coincide with grammatical units. The symbol " $F$ " means the formal sign chain unit really used in talking situations and corresponding to a $L P C=L P I$ unit produced in that talking act. It is the actual linguistic sign chain, or a chunk of it, actually used in the talk act (Axiom 3). When people talk (orally or in writing) they do not always use complete sentences, they might used broken-up chunks of sentences which nevertheless seem to make sense (this "making sense" means here "producing a linguistic perception intended and comprehended"). (We will write " $F_{0}$ " for a unit of a given language "o".) This linguistic unit consists, of course, of a surface structure Xm and a semantic structure $S m$ which can be written thus: $\mathbf{F}_{\mathbf{0}}(\mathbf{X m}+\mathbf{S m})$.

It is useful to call this expression a "formal space" as contrasted with the "perceptual space" (as defined in propositions (2) and (3c) below). We can then usefully analyze the relationships of formal spaces to perceptual spaces as they exist only within the act of talking-thinking (see Theorem 1).

DEFINITION No. 6: THE LINGUISTIC SIGN SYSTEM Symbol: L (EXPONENT)

$\mathrm{L}$ is the sign system (in Saussurian French "la langue"), that is, the "systemic nature of language" as different from the actual sign chain. We can visualize it as a set of rules and a dictionary. The "Linguistic sign systems" are the objects studied by all branches of linguistics. They never actually happen at any moment in time. The only thing we find actually happening in time and space (in talking acts) are sign chains. We infer from the regularity of actual sign chains that there is somewhere a system. (The word "code" is not appropriate because a linguistic sign system is much more complex and infinitely more flexible than a code.) To make a distinction between entities which do not actually exist and those which do we will write the symbol $\mathrm{L}$ as an exponent affecting a given sign chain Xm.

$X m^{L}$ refers to the fact that the sign chain Xm belongs to and is the actualization (manifestation) of the sign system L. The specific linguistic system used by the Speaker will be called "o" (Orator) (Source Language) and the specific sign system used by the Interpreter will be called " $i$ " (Interpreter) (Target Language). As we said before, $F_{o}$ means a linguistic unit actually used belonging to the linguistic sign system " $\mathrm{O}$ ", $F_{\mathrm{i}}$ means a unit actually used belonging to the sign system " $i$ ", etc.

\section{DEFINITION No. 7: THE SEMANTIC SYSTEM Symbol: H (EXPONENT)}

This is the total semantic system of a given linguistic sign system. It is a part of $L$ but it is useful to consider it apart. It can be processed as semantic paradigms or semantic fields. In our notation, it will appear as an exponent of the Semantic potential Sm of a given chain $\mathrm{Xm},\left(\mathrm{Sm}^{\mathrm{H}}\right)$ ) signifying as in the previous definition two things: $\left.\mathrm{i}\right)$ the relation of the actual semantic potential of a given sign chain as uttered to the semantic system, and ii) the relationship between the system and the process. The idea here again is to distinguish clearly between different entities quite often confused. The semantic system can be said to include, among other things, the "semantic fields", for ex., the fact that "bois" 
in French covers the same semantic field as "Holz" and "Wald" in German. Or the fact that the semantic field of "yes" in English covers the French field "oui". These semantic fields belong in the system because they can be said to "exist" outside the social acts of talking-writing whereas $\mathrm{Xm}$ and $\mathrm{Sm}$ are actualities. This means that $\mathrm{F}, \mathrm{Xm}, \mathrm{Sm}$ only exist in "talking-thinking processes", not in "sign systems".

\section{DEFINITION No. 8: THE KNOWLEDGE BASE Symbol: K (EXPONENT)}

Everything that is necessary to know to be able to understand what speakers mean, first of all the encyclopedia, but most importantly, knowledge of the subject under discussion. K can be axiomatized. Linguistic perceptual spaces emerge from and are part of social and, therefore, shared knowledge bases. All knowledge bases have a structure and this structure reveals that they are all connected in a great network which constitues the general matrix of a subject or of a given historical period (Kuhn's hypothesis but also the Safir-Word hypothesis about "Weltanschauung"). Linguistic perceptual spaces, as produced in talking acts, are the result of cognitive processes in which knowledge bases play a decisive role.

\section{DEFINITION No. 9: BELIEFS, NORMS, PRACTICES Symbol: P (EXPONENT)}

This definition refers to the rules that govern the social transaction of talking ("language event"). These rules can also be presented as the set of beliefs, norms, practices and customs, written or unwritten, more or less conscious but probably amenable to awareness (including rules of saying things, that is, rhetorical rules or habits or manners of speaking) of a community which determine or influence the behavior of social agents as speakers. Speakers have to know these rules, at least indirectly, to be able to understand what speakers mean ${ }^{8}$. Sometimes they can be analyzed, verbalized, studied even if they are not "explicit ideas" or thoughts or propositions. It might perhaps be conceivable that at least some of them can be axiomatized so as to enable a computer to deduct "language comprehension" according to rules but this is mere guessing or maybe wishful thinking. Another and perhaps more useful way of conceiving this variable $P$ is to see it as the life experience of the talking subjects, including the personal and professional experience. To understand a book you have to know what is the life and professional experience of the author. (To understand this text you have to know that its author is a professional translator and conference interpreter as well as a "doctor of sciences and techniques of interpretation and translation" as my title says in French.)

\section{DEFINITION No. 10: SOCIAL SITUATION OF THE TALK ACT Symbol: G}

$\mathrm{G}$ is the social context of the talk act. This social situation is the set of extralinguistic variables, non-systemic in nature (non-exponential), necessary to construct an LPC (necessary to understand what speakers want to say). In oral talking, this set includes information about social relations, interests and attitudes and background of people present, what is at stake, including visual data from looks, body movements, face expressions and gestures of speakers. It also includes, I guess, knowledge of everything that has been previously said. As $G$ is a moment in time and space, we will write $G_{\text {tn }}$ to indicate that the social transaction is happening in time $n$. It is useful to think of $\mathrm{G}$ as the scene $\mathrm{X}$ of act $\mathrm{Y}$ of theater play $\mathrm{Z}$. Knowledge of those relationships and interests is necessary to comprehend what speakers are saying or trying to hide or communicate without saying (implicit). According to our definitions the socio-mental percepts LPI and LPC can only exist in socially situated talking transactions (talk acts). In written talking $G$ includes the social-historical field. 


\section{THEOREM 1: GENERAL MODEL OF THE ACT OF TALKING-THINKING (LANGUAGE EVENT)}

Let us call it "Discourse of the Orator", symbol "Do"9. We refer here to the simplest form of the act of talking-thinking, namely, the situation where there are two speakers talking to each other, a Speaker ("orator") speaking and a Hearer ("interpreter" because all hearers are interpreters as they have to understand what is said) listening and understanding. The model tries to describe a single unit of "comprehension", not the continuity of comprehending. That is, the model refers to a time stretch of approximately 250 milliseconds of a normal "speech chain". So understood our model of "Do" - which is a process of speech/thinking/manipulating signs according to their value in that situation has the following structure (common to all "language games"):

$$
\text { (1) Do: } \operatorname{LPI}_{0} \mathrm{~K}-\mathbf{F}_{\mathrm{o}}\left(\mathbf{X m}^{\mathrm{L}}, \mathrm{Sm}^{\mathrm{H}}\right) \mathrm{G}_{\mathrm{tn}}{ }^{\mathrm{P}}-\mathrm{LPC}_{\mathrm{o}} \mathrm{K}
$$

This way of writing tries to present in a condensed form, easy to remember and to analyze, what in fact is a very complex thought. The proposition (1) means that a talkingthinking act (language event) is a social transaction in which

- someone (subject of production) wants to say something (wants to produce an $\mathrm{LPI}_{\mathrm{o}}$ - mental representation - which is a part of a given knowledge base $\mathrm{K}$ ) and to that effect he sets in motion a complex thinking operation which consists mainly of constructing and presenting to the other person a finished social product which is a sign chain unit $F_{o}$ (with a given surface structure $\mathrm{Xm}$ - which is the actualization of a system $\mathrm{L}$ - and which is endowed with a semantic potential $\mathrm{Sm}$ - as the actualization of a semantic system $\mathrm{H}$ ) in a given social situation (or social-historical field) $\mathrm{G}$ - at a time "tn" - (this social situation being the manifestation of $\mathrm{P}$, that is, a certain set of rules or beliefs, customs, social practices or, you could say, a certain life and professional experience),

- and someone else (subject of comprehension), also called "the interpreter", (but it could be - and normally is - the same person playing both roles), is listening and understanding in a complex thinking operation which results in that he is "seeing" something, namely producing a perception, an $\mathrm{LPC}_{o}$ (which is a propositional or mental or perceptual representation part of the same $\mathrm{K}$ ). The subindex "o" means in this case that both percepts and sign chain units belong to the same language event called "Do". And of course we postulate some sort of identity between what the speaker wants to say (an $\mathrm{LPI}_{0}$ ) and what the hearer comprehends (an $\mathrm{LPC}_{\mathrm{o}}$ ), otherwise there would be no communication. This "sort of identity" could be expressed as:

$$
\text { (2) } \mathbf{L P C} \mathbf{o}_{\mathbf{o}}=\left(\mathbf{G}_{\mathrm{tn}}\right)=\mathbf{L P I}
$$

To somehow compensate for this wildly schematic way of presenting the complex reality of the "language event" or "act of talking" we could make at least some cursory comments:

i) This structural model applies to all kinds of "language games" or all kinds of "speech", whether it is so-called "social or outer speech" or "inner speech" or whatever. All "speech" is a social transaction involving at least two real or imagined actors (me speaking to myself) - actors, by the way, created by their role in the talking game - involving the production of sign chains of some sort, even if they are "internal sign chains", involving the actualization of knowledge bases and life experiences, in a given social situation which is part 
of a social-historical field. Our model is static, it does not describe the thinking activity which goes on all the time while we talk.

ii) The set of exponents KLHP define a social gravitational field, in which orbits are inscribed which determine the possibilities of specific social actions by specific human subjects ${ }^{10}$. These individual actions are facts happening at a given time and space as represented by the mantissas LPI, LPC (which are specific actions of specific persons) and also $\mathrm{G}$, which is a specific fact, and sign chains of the kind Xm, which are specific things. The field KLHP is not a specific fact but... a field.

iii) As we hinted in the introduction, the theorem of the social act of talking-thinking is not only a theory of sign and a theory of meaning but also a general theory of language, that is, a model of thinking, that is, of "language understanding" and of a social act (in short, a philosophy of mind, "mind" being not an individual attribute but the social network of Linguistic Percept production = production of social reality).

Suppose the hearer who has understood (who has produced an LPC), turns to someone else - who does not understand the sign system "o" - and says the same thing in the sign system " $\mathrm{i}$ " (transforming his LPC into an LPI). He would launch a new language event (a new act of talking-thinking), the "Di" (Discourse of the Interpreter). This new talking event is a new process but it has the same structure as the "Do":

$$
\text { (1a) Di: } \mathbf{L P I}_{\mathbf{i}}^{\mathrm{K}}-\mathrm{F}_{\mathbf{i}}\left(\mathbf{X n}^{\mathrm{L}}, \mathrm{Sn}^{\mathrm{H}}\right) \mathbf{G}_{\mathrm{tn}} \mathbf{P}-\mathrm{LPC}_{\mathbf{i}} \mathrm{K}^{\mathrm{K}}
$$

\section{THEOREM 2: GENERAL MODEL OF TRANSLATION}

To translate is to talk to re-say the said as such. This means that to translate is to speak again. Therefore, there is a first talking-thinking act (Do) and then the translator speaks his own talking-thinking act (Di) to re-produce, in another sign system (called here system " $i$ "), a given linguistic percept $\left(\mathrm{LPC}_{\mathrm{o}}=\mathrm{LPIC} \mathrm{C}_{\mathrm{o}}\right)$, thereby producing a new linguistic percept $\left(\mathrm{LPI}_{\mathrm{i}}=\mathrm{LPC}_{\mathrm{i}}\right)$. The model of translation presents in fact the coexistence of two talking-thinking acts (two language events):

\section{(3a) Do - Di}

and, the same idea, fully developed:

$$
\text { (3b) } \mathrm{LPI}_{\mathrm{o}}{ }^{\mathrm{k}}-\mathrm{F}_{\mathrm{o}}\left(\mathrm{Xm}^{\mathrm{L}}, \mathrm{Sm}^{\mathrm{H}}\right) \mathrm{G}_{\mathrm{tn}}{ }^{\mathrm{P}}-\mathrm{LPC}_{\mathrm{o}} \mathrm{K}^{\mathrm{K}}==\mathrm{LPI}_{\mathrm{i}}^{\mathrm{K}}-\mathrm{F}_{\mathrm{i}}\left(\mathrm{Xn}^{\mathrm{L}}, \mathrm{Sn}^{\mathrm{H}}\right) \mathrm{G}_{\mathrm{tn}}{ }^{\mathrm{P}}-\mathrm{LPC}_{\mathrm{i}}{ }^{\mathrm{K}}
$$

and there is translation if

$$
\text { (3c) } \mathrm{LPC}_{\mathrm{i}}^{\mathrm{K}}=\left(\mathrm{G}_{\mathrm{tn}}\right)=\mathrm{LPI}_{\mathrm{o}} \mathrm{K}
$$

The identity $3 c$ represents the sine qua non condition for translation to exist. We speak then of translation identity or identity of the said as such (the "message" has been exactly reproduced) but they are equal "through" a social context (social situation or social-historical field) which forms an integral part of the meaning involved. The proposition $3 c$ is in fact a shorthand version of $3 b^{11}$.

\section{THEOREM 3: SEMANTIC EQUIVALENCE AND TRANSLATION EQUIVALENCE}

Semantic equivalence is the equivalence in a bilingual dictionary (isolated from any talking act) of two sign chains: 
(4) $F_{o}(X m, S m)-F_{i}(X n, S n)$

Example: "hat" is the semantic equivalent of "chapeau" (but in a given translation who knows what the English equivalent of "chapeau" could be? The "chapeau" of a chapter is its initial paragraph, not its "hat").

Whereas "translation equivalence" of two sign chains $F_{o}$ and $F_{i}$ is the equivalence of those two same expressions if and when they are used in a double talking act as in (3b), that is, when they are united by a common percept. We write "translation equivalence" as follows:

$$
\text { (5) } \mathbf{F}_{\mathbf{i}}(\mathbf{X n}, \mathrm{Sn})-\mathbf{L P I}_{\mathbf{i}}=\left(G_{\mathrm{tn}}\right)=\mathbf{L P C} \mathrm{C}_{\mathbf{0}}-\mathbf{F}_{\mathbf{o}}(\mathrm{Xm}, \mathrm{Sm})
$$

\section{THEOREM 4: LITERALITY}

We speak of "literality" if in a situation of the type (3), apart from having a translation identity of the type (3c), - which is necessary for translation to exist - we also have a similitude of surface structures $\mathrm{Xn}-\mathrm{Xm}$ and/or semantic potentials $\mathrm{Sn}-\mathrm{Sm},-$ which is not necessary for translation to exist. Literality, therefore, is the simultaneous presence of translation equivalence and linguistic equivalence. We are thinking, of course, of the kind of literal translation where the condition of identity of the said as such (3c) is satisfied. We could write that literality is the similarity of formal spaces in a double translation talking act:

$$
F_{o}(X m, S m)=F_{i}(X n, S n)
$$

if those two formal spaces are part of

(3b) $\mathrm{LPI}_{\mathrm{o}} \mathrm{K}^{\mathrm{K}}-\mathrm{F}_{\mathrm{o}}\left(\mathrm{Xm}^{\mathrm{L}}, \mathrm{Sm}^{\mathrm{H}}\right) \mathrm{G}_{\mathrm{tn}}{ }^{\mathrm{P}}-\mathrm{LPC}_{\mathrm{o}} \mathrm{K}^{\mathrm{K}}==\mathrm{LPI}_{\mathrm{i}}{ }^{\mathrm{K}}-\mathrm{F}_{\mathrm{i}}\left(\mathrm{Xn}^{\mathrm{L}}, \mathrm{Sn}^{\mathrm{H}}\right) \mathrm{G}_{\mathrm{tn}}{ }^{\mathrm{P}}-\mathrm{LPC}_{\mathrm{i}} \mathrm{K}$

\section{ANNEX I}

The two definitions, LPI and LPC, define together one single object, namely, the said as such. The said as such is the real "object" of all language events and the real "object" of the science of language, which is not about sign systems (the specific subject matter of Linguistics) but rather about the production of linguistic perceptions. Linguistic perceptions are, however, only visible in translation theory. The best definition one can give of linguistic perception is "a linguistic perception is the object that gets translated in all translation".

A Linguistic Percept is not merely an LPI, it is not merely an LPC, it is rather the identity between these two as expressed by the proposition (3c). LPI or LPC are not things, they are just two different aspects or moments of the totality of the language event of talking-thinking. The real thing is the relationship between the two as expressed by (3c). We are, nevertheless, obliged to present these two aspects of the same thing as two separate definitions but we hope it is clear that they are not separate entities but two different aspects or moments of the same reality, namely, the totality of the language event. We define this object as a social object. Language is not a faculty of the individual but a social communication network. Of course, you need a certain type of brain to be able to enter the network and, of course, brains are individual properties, but the network is a social entity. Linguistic Percepts are also called "ideas" and ideas are not only psychological events but rather social objects circulating in the language network. It so happens that those LPs are the constituents of social reality. 


\section{ANNEX II}

One of the advantages of our symbolic notation is that a long and complicated theory can be written in a very small space avoiding the typical verbosity and consequent imprecision of social science texts which make it impossible to compare and create a common terminology, every author using his own terminology in such a way that it is incompatible with other people's terminology. On the other hand, symbolic notations have a disadvantage in that the consequences of a theory presented in symbolic notation are not immediately apparent. As far as our general model of the language event (talkingthinking) is concerned, we have already pointed out that this model is also a theory of the sign and, therefore, a theory of meaning: it presents meaning as a complex relationship between perceptions and sign-chains in a social-historical field $G$ happening in a gravitational systemic totality KLHP. This relationship is expressed by:

$$
\text { (1) Do: } \mathbf{L P I}_{\mathbf{o}} \mathrm{K}-\mathrm{F}_{\mathbf{o}}\left(\mathrm{Xm}^{\mathrm{L}}, \mathrm{Sm}^{\mathrm{H}}\right) \mathrm{G}_{\mathrm{tn}}{ }^{\mathrm{P}}-\mathrm{LPC}_{\mathbf{0}} \mathrm{K}^{\mathrm{K}}
$$

where we see the complex relationship between a "formal space" $\mathrm{F}_{\mathrm{o}}\left(\mathrm{Xm}^{\mathrm{L}}, \mathrm{Sm}^{\mathrm{H}}\right)$ and a "perceptual space" $\mathrm{LPC}_{\mathrm{i}} \mathrm{K}=\mathrm{G}_{\mathrm{tn}}=\mathrm{LPI}_{\mathrm{o}} \mathrm{K}$ as it presents itself embedded in the totality of a language event where the presence of speakers and a public occurs in a social-historical field $\mathrm{G}$ at time $n$. It is therefore wrong to write

$$
\text { "formal space" } \mathrm{F}_{\mathrm{o}}\left(\mathrm{Xm}^{\mathrm{L}}, \mathrm{Sm}^{\mathrm{H}}\right)-\ldots \text { "perceptual space" } \mathrm{LPC}_{\mathrm{i}}^{\mathrm{K}}=\mathrm{LPI}_{\mathrm{o}} \mathrm{K}
$$

We should rather write:

$$
\text { (1) Do: } \mathbf{L P I}_{0}{ }^{\mathrm{K}}-\mathrm{F}_{\mathrm{o}}\left(\mathrm{Xm}^{\mathrm{L}}, \mathrm{Sm}^{\mathrm{H}}\right) \mathrm{G}_{\mathrm{tn}}{ }^{\mathrm{P}}-\mathrm{LPC}_{\mathrm{o}} \mathrm{K}^{\mathrm{K}}
$$

or, in shorthand $F_{o}\left(\mathrm{Xm}^{\mathrm{L}}, \mathrm{Sm}^{\mathrm{H}}\right)$ _ _ "perceptual space" $\mathrm{LPC}_{\mathrm{i}} \mathrm{K}=\mathrm{G}_{\mathrm{tn}}=\mathrm{LPI}_{\mathrm{o}} \mathrm{K}$.

It is only in this totality of the language event that we can analyze the complex relations between formal and perceptual spaces. Perceptual spaces are not possible and cannot exist without formal spaces in language events. Nevertheless, perceptual spaces are separable from formal spaces as is revealed by the Jarvella effect and by the language game we call translation. On the other hand, these complex relations between formal and perceptual space say nothing about the possible and also complex reference to something outside "language". Whatever this reference is, it is not simple.

This general model of a language event is also a model of language comprehension 12 .

\section{NOTES AND BIBLIOGRAPHY}

1. This symbolic notation has absolutely nothing whatsoever to do with mathematical notation except inasmuch as it is also an attempt to express ideas clearly by numbering and defining the main terms (concepts) used and the syntactic relations that unite them to build propositions. We cannot deny, however, that this implies a criticism of the way of writing of social scientists. (See Annex II)

2. Steiner, in After Babel, gets hold of the real theoretical problem, namely, the distinction between the systemic value of isolated sign chains and the value of the message, but then in an incomprehensible move coming from someone who is writing such a book on translation, goes on to demand that this distinction should be proved when it is in fact, as his book amply and brilliantly shows, the monumental and millenarian experience of all translators. Referring to St. Jerome's famous sentence, Steiner writes:

"In whatever form it is put, non verbum e verbo sed sensum exprimere de sensu assumes precisely that which requires demonstration. It predicates a literal meaning attached to verbal units, normally envisaged as single words in a purely lexical setting, which differs from, and whose straightforward transfer will falsify, the "true sense' of the message". After Babel, OUP, 1975, p. 276. 
3. "All communication between source and receptor, even within one's native tongue, has been recognized as analogous to the modes of meaning-transfer between languages... there can be no genuine 'theory of translation' so long as there is no satisfactory 'theory' of how the human mind produces meaningful speech... such a 'theory of translation' would be a working model of the imprint, storage and generation of human speech itself." G. Steiner in After Babel, OUP, 1975. Yes, but what this means is simply that a theory of talking is a theory about "speech and thought" that is, a theory of thinking.

4. In fact, they are not "extra"-sensorial but rather "supra"-sensorial because we perceive sensorially the acoustic waves which carry the phonological form of spoken speech (or we "see" the specks of ink which by a long and hard training remind us of those original acoustic perceptions). Animals dispose of perceptual systems that allow them to move around. Humans have developed a special perceptual system - or a special perversion of their perceptual system - using artificial signs and symbols on top of their animal perceptual system. We call it "language". It is not, however, an individual characteristic but rather a social network. (What we call "mind" is not an individual characteristic either but a social one.) The main function of this second social perceptual system is to produce new kinds of perceptions which we can call for lack of a better word "linguistic perceptions" (LPs). The "linguistic perceptions" produced in social transactions are what we call "social reality", the habitat of h.loquens. Humans do not live in nature but in an artificial habitat constructed with linguistic perceptions (LPs). Now we know why it is so difficult to construct a real theory of translation, namely because such a theory would have to be a theory of talking and that is nothing less than a theory of construction of social reality.

5. The fully developed version of the theory operates with more definitions like for example register, rhythm, a variable called "what-has-previously-been-said", another called "world", etc., but this is a limited version.

6. There is a problematic relationship between theory and experience in social sciences. Modern science was born in the 16th century when it was accepted that scientific propositions must have a direct relationship with observable facts, if possible repeatable in "laboratory" conditions. This principle does not yet apply in the social sciences. Some people write about translation without having any experience of translating only a professional translator can have that experience - and, therefore, what they write, although sometimes interesting per se, as interesting as science fiction can be, bears no relationship whatsoever with the real world of translation. They are victims of the social naive prejudice conveyed by everyday speech that translating is changing the words. On the other hand, one has to admit that there is a circle here because the description of social experience is impossible without a set of theoretical hypotheses. If you ask experienced translators or conference interpreters to describe what they do you will notice that they usually cannot say anything meaningful at all about it. But nevertheless it is quite clear that some theories describe better the experience of translation than others. My description of what it is that I do when I translate a text or interpret a speech at an international conference might be a repetition of my theory but I feel it describes better what $I$ do and it is a way of discovering hidden aspects of that very experience.

According to my model of translation, to translate is to listen/read and then to understand what the speaker/author is trying to say "in spite of his/her words", and to take that and forget about his / her words and say it again in another sign system with the means that this other sign system puts at your disposal. To understand what the speaker/author is trying to say (always sort of hidden behind his/her words), you have of course to know that sign system but also the subject and the context. This is easier to do in oral translation (conference interpretation) because oral signs are not as solid as written signs, which means that the context is more present and you do not have to "respect" those signs. In written translation you have to do with solidified objects and you almost always fall victim to the silly temptation of trying to reproduce "words" instead of "what the man means". Whenever people discuss translation they quite often tend to fall for this kind of silly temptation and ask themselves how it is possible to find equivalents for that "word" in the other sign system. This is, of course, the temptation of Machine Translation. And if you are dealing with sign systems belonging to the same family (sister languages), like French and Spanish or even English and Spanish, it is almost possible to translate mechanically "word for word", forgetting that, first of all, you have to understand what someone means and only after having understood that and by projecting it in the sign chains, you are able to identify words as meaningful units. The real nature of translating, namely, that it is just talking to reproduce, not "words" but "ideas", is more visible when you translate from widely different sign systems, from Japanese into English, for example. But even this last sentence is wrong, because you do not translate from a sign system to another but from a mental event to another.

7. These definitions refer to two kinds of objects: processes and systems. Processual objects are either human actions (someone uttering a sign chain ) or social acts (a given social situation), all of which happens in physical time-space ("synchronic" events in Saussure's terminology). Systemic objects, on the other hand, are "diachronic" happenings, like "sign systems" or "social knowledge bases" or "beliefs", etc., which do not happen in physical time-space (we cannot say "the English language happened yesterday night at eleven hours") but in "historical time". These systemic objects function in our theory like social gravitational fields which set up orbits which in tum define the possibilities for action. (A given linguistic sign system, 
English for example, defines the kind and number of sentences which I can construct, etc.) To mark the fundamental distinction between systems and processes in our symbolic notation we write processes as "mantissas" and systems as "exponents". This kind of writing has, of course, absolutely nothing to do with the meaning of mantissas and exponents in mathematical writing. Their use here is purely conventional and, if at all, metaphorical. But we have gotten so used to that writing convention that we sometimes speak of "exponential objects" instead of "systemic objects".

The difference between the two is fundamental in modern thought. Suffice to make a rapid allusion: systemic objects have been the pets of structuralists, while processual objects are the entities that inhabit Heidegger's Being and Time.

8. Among Searle's contributions to the post-wittgensteinian philosophy of language, let us mention his concept of intentionality of speakers as the support of meaning meant - which we can now complete with the notion of the perception perceived by the hearers at the other end of the "language event" - and his notion of beliefs as a necessary variable to comprehend what people have the intention of saying but which are not amenable to propositions, that is, not capable of being axiomatized (not translatable into a language understandable by a computer). See John P. Searle, "Six Principles for the Comprehension of Language", in Actes du Colloque "Comprendre le langage". Université de Paris XII, September 1980 and also Intentionality. An Essay in the Philosophy of Mind, CUP, 1983.

9. The oddity of this expression comes from the fact that these ideas were first expressed in French and by reference to the experience of OST (oral simultaneous translation, also called "conference interpretation") where there is a first language event going on between an "Orator" or public speaker and an Interpreter who is there to professionally understand and then to launch a second language event to reproduce the Linguistic Percept produced in the first language transaction.

10. M. GARCIA-LANDA (1984): "Práctica y teoria de la interpretación", in Quadernos de traducción e interpretación, vol. 4, EUTI, Universidad Autónoma de Barcelona.

11. We consider that the identity (3c) represents a social object. This translation model operates with three variables: $\mathrm{F}_{\mathrm{O}}, \mathrm{F}_{\mathrm{i}}$ and $\mathrm{LPC}_{\mathrm{i}} \mathrm{K}=\mathrm{LPI}_{\mathrm{O}} \mathrm{K}$ whereas previous models operate only with the first two. Machinetranslation projects try to find complex algorithms for the equivalence $F_{0}-F_{i}$ fearing perhaps, as the behaviorists, anything "mental" when in fact once the object $\mathrm{LPC}_{\mathrm{i}} \mathrm{K}=\mathrm{LPI}_{\mathrm{O}} \mathrm{K}$. has been sufficiently defined it is perfectly possible to find a way of mapping it into a representation system understandable by any AI entity, the best being probably found in a development of the symbolic notation used by conference interpreters in the consecutive mode.

12. M. GARCIA-LANDA (1981): "La théorie du sens, théorie de la traduction et base de son enseignement", Revue de l'Université d'Ottawa, vol. 51, no. 3, July-September, and also "La teoría de la traducción y la psicología experimental de los procesos de percepción del lenguaje", Estudios de psicología no. 19-20, Madrid, 1985 